\title{
From waste incineration by-products to functional materials: a "Chimie douce" route to VOCs mineral adsorbents
}

\author{
Alexis Corbin ${ }^{1} \cdot$ Lise Guichaoua ${ }^{1} \cdot$ Hiva Baradari ${ }^{1}$ - Flavien Gueneau ${ }^{1} \cdot$ Xavier Chaucherie $^{2}$ Bruno Gilardin ${ }^{2}$. \\ Thierry Gosset $^{2} \cdot$ Cédric Boissière $^{1} \cdot$ Lionel Nicole $^{1}{ }^{1} \cdot$ Clément Sanchez $^{1}$
}

Received: 25 October 2021 / Accepted: 21 January 2022 / Published online: 18 February 2022

(C) The Author(s) 2022

\begin{abstract}
One of today's major world challenges is the accumulation and the storage of tens of millions of tons per year of final materials resulting from the incineration of domestic and industrial waste. This raises the question of the recycling of these "raw materials", while making allowance for environmental, economic, social and public health aspects. Our strategy targets the incorporation of waste incineration by-products in a totally circular economy. We propose an innovative process combining templated sol-gel growth of an inorganic or hybrid silica-based network with a solubilized fraction of bottom ash coming from the combustion of industrial and household wastes. The resulting materials engineered via aerosol processing demonstrate maximum adsorption capacity of model pollutant compounds (1-2 dichlorobenzene) competitive with activated carbons currently used in modern incineration plants. We believe that they have the potential to replace conventional activated carbon commonly used in incineration plants, enabling the first step of the long road of recycling final waste.
\end{abstract}

Supplementary information The online version contains supplementary material available at https://doi.org/10.1007/s10971022-05731-1.

Lionel Nicole

lionel.nicole@ sorbonne-universite.fr

$\triangle$ Clément Sanchez

clement.sanchez@college-de-france.fr
1 Sorbonne Université, CNRS, Collège de France, PSL, UMR 7574, Laboratoire de Chimie de la Matière Condensée de Paris (LCMCP), 4 place Jussieu, 75005 Paris, France

2 SARPI-VEOLIA, Direction Technique et Innovation, 427, route du Hazay, 78520 Limay, France 


\section{Graphical abstract}

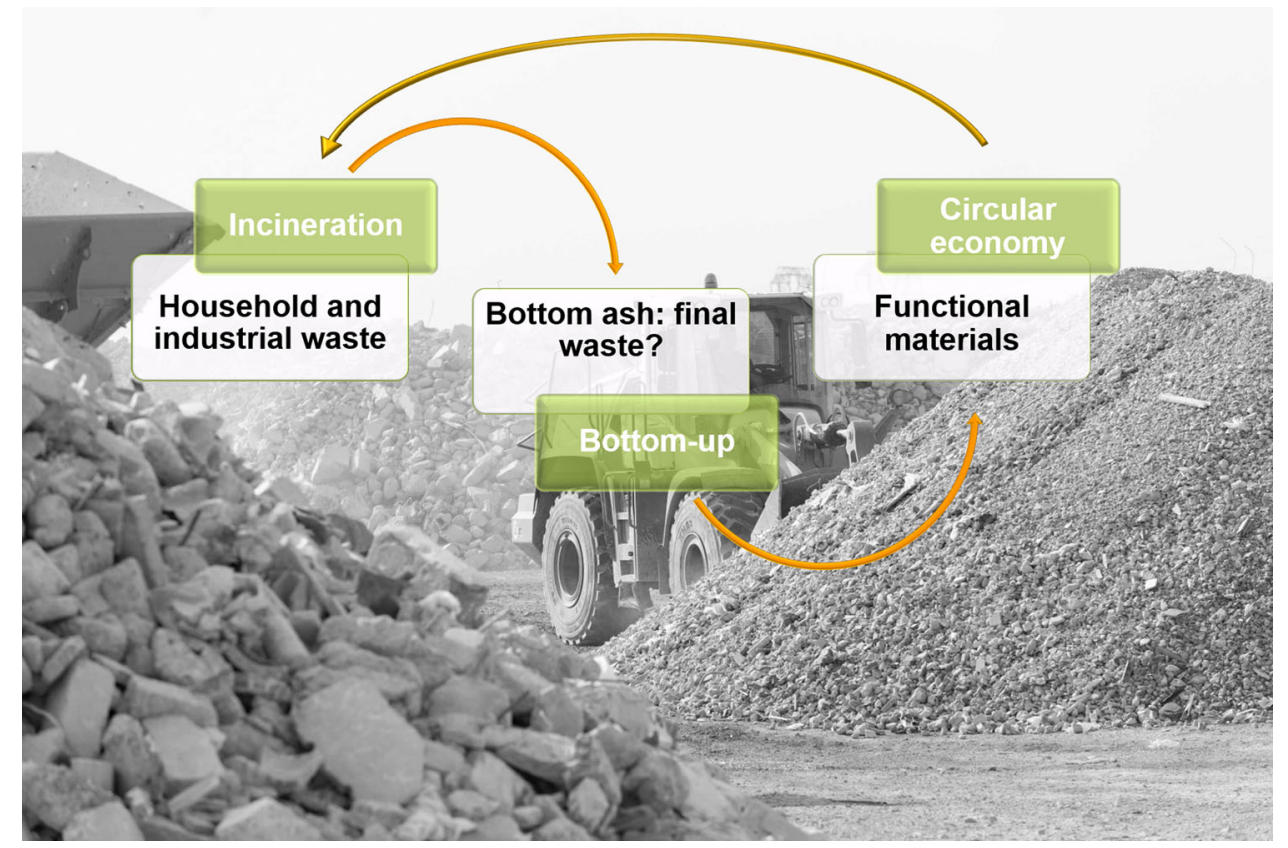

Keywords Bottom ash $\cdot$ Spray drying $\cdot$ Recycling $\cdot$ Incineration $\cdot$ Sol-gel $\cdot$ Gaseous pollutants adsorption

\section{Highlights}

- Sol-gel process combined with spray-drying enables part of bottom ash to be recycled.

- Mesoporous silica-based particles with a high content of bottom ash derivatives were synthesized.

- Composite particles display promising adsorption properties towards gaseous model pollutants.

\section{Introduction}

The management of solid waste is a critical issue which involves and impacts all the persons living on earth. For example, each year, 2.01 billion tons of Municipal Solid Waste (MSW) are generated and it is expected that global waste will reach 3.40 billion tons by 2050 [1]. Besides, MSW present a very wide range of constituents including food and green, plastic, metal, glass and ceramic, cardboard and paper, rubber and leather, etc, with a "composition" which varies on a daily basis and between regions, leading thus to waste management difficulties. According to World Bank figures, almost $37 \%$ of MSW ends up in landfills, $33 \%$ is openly dumped, $19 \%$ is recycled and composted, and finally, $11 \%$ is incinerated in modern plants with fly ash and bottom ash as final solid byproducts [1]. Landfills and open dumping inducing air, water and soil pollution, greenhouse gas emissions, diseases and natural resources wastage cannot be seen as a sustainable solution in the future [2]. On the contrary, it is obvious that jointly with decreasing the amount of MSW, recycling and composting are the best available alternatives. However, they require specific waste collection and/or waste sorting, recycling channels and applications/ markets for recycled materials which could hinder their rapid development. Thus, incineration with energy recovery constitutes a medium-term alternative which contributes to a high mass and volume waste reduction (70\% and $90 \%$ respectively) [3]. For this reason, it could explain that waste incineration is often considered as the best-cost effective solution for treating household and industrial waste because of landfilling reduction [4]. Incineration processes present also several additional advantages such as destruction of hazardous organic materials, reducing risks due to pathogenic bioorganisms (microbes, bacteria and viruses) and concentrating materials potentially of interest as well as toxic metals [5]. However, the mass and volume reduction are obviously accompanied by a release of atmospheric pollutants in the flue gas $[2,5,6]$. Atmospheric pollutants comprise generally $\mathrm{SO}_{2}, \mathrm{NO}_{\mathrm{x}}, \mathrm{N}_{2} \mathrm{O}, \mathrm{HCl}, \mathrm{HF}, \mathrm{CO}, \mathrm{CO}_{2}$, dioxins, furans, polycyclic aromatic hydrocarbons, VOCs and heavy 
metals $(\mathrm{Hg}, \mathrm{Cd}, \mathrm{Pb}$, etc) [2]. Since the first incinerators operating at the end of the $18^{\text {th }}$ century, a lot of scientific and technical improvements have been done on the basis of energy recovery (electricity and/or heat production) or in relation with increasingly binding legislation including strict limitation of toxic compound emissions in the offgas $[5,7]$. For example, in the European Union, incinerator temperatures have to reach at least $850^{\circ} \mathrm{C}$ for two seconds in order to decompose significantly toxic organic compounds and up to $1100{ }^{\circ} \mathrm{C}$ if waste contains halogenated organic substances [8]. Temperature control during the combustion process is not the only way to limit toxic compounds emission and new technologies of filtration, with modern multi-stage filter systems and effective air pollution control, have been developed to fulfill constraining legislation requirements [5]. After the combustion process, solid residue representing around $30 \%$ of the initial solid mass of waste is composed of fly ash ( $~ 5 \%)$ and bottom ash ( 25\%). The solid residue composition, depending directly on the uncontrolled composition of industrial and/or household waste, could thus vary greatly day by day in the same incineration plant and during the same day between plants located in different regions. This observation makes it difficult to design a holistic strategy for recycling incineration waste. Due to their intrinsic properties close to natural materials, their constant increase linked to the increase of human activity and limitations of landfilling, the reuse of bottom ash in construction applications has become a standard practice especially for road construction (asphalt concrete, pavement, roadbed aggregates) [9]. However, bottom ash may contain amounts of hazardous compounds which could, after leaching processes due to rainwater, contaminate soils, water tables, and groundwater leading to flora and fauna pollution [4]. Their use as raw materials in construction applications has thus been subjected to new regulatory limitations leading to the development of new treatments aiming to reduce their potential toxicity [10].

The reuse of bottom ash as construction materials is not nevertheless the only option. Indeed, bottom ash may be seen as an interesting ore which can be treated in order to separate, extract and concentrate raw materials of interest (iron, aluminum, copper, zinc, silicon, etc, mainly in crystallized oxides form) for a further use [5, 11]. Indeed, compared to mining, extraction of raw minerals from incinerator waste requires less energy, water, transportation, materials and land and present a lower impact on the environment (less pollution with modern incineration plants) [5]. Another advantage of recycling incinerator waste involves economic aspects with a better control of resource production. Since resource price depends on their worldwide availability and to a lesser extent geopolitical consideration, a generalized local and continued production could limit raw material scarcity and thus reduce the high volatility of their prices [5].

Following a five-year project aiming to recycle bottom ash coming from industrial and household waste, we developed an industrial-scale recycling scheme for incineration of solid by-product. After bottom ash grinding and sieving, an acidic dissolution process produces quartz-rich solid residues and a leachate solution which is spray-dried to form high surface area porous particles [12]. Almost 80\% of the initial amount of bottom ash is recycled by this way and the remaining $20 \%$ could also be used in construction applications by coupling microwave treatment with sol-gel chemistry leading to highly resistant porous monolithic materials [13]. This article will focus on the robust synthesis of spray-dried mesoporous particles containing a high fraction of solubilized waste residue displaying maximum adsorption capacity for model organic pollutant compounds (1-2 dichlorobenzene), which is competitive with activated carbon. The synthesis developed in this article is particularly well-suited to the high composition variability encountered with bottom ash and leads to highly reproducible mesoporous particles regardless of the type of bottom ash used (e.g., coming from industrial or household waste). Spray-drying processing of solutions was selected for producing particle size distributions compatible with modern multi-stage filtration incinerator systems. They are intended to replace activated carbon commonly used in incineration plants after pilot tests at larger scale.

\section{Experimental section}

\subsection{Synthesis of the composite materials}

After grinding, sieving and extraction steps, residue of bottom ashes is treated in $37 \% \mathrm{HCl}$ solution for $1 \mathrm{~h}$ and then filtered in order to collect stable and transparent leachates. In this study, four different leachates have been used coming from different locations in France at different periods. Despite these differences, leachate compositions are surprisingly similar and variations are mainly related to species concentrations (inorganic ions of $\mathrm{Cl}, \mathrm{Ca}, \mathrm{B}, \mathrm{Fe}, \mathrm{Co}, \mathrm{Al}, \mathrm{Na}$, $\mathrm{K}, \mathrm{Mg}, \mathrm{Zn}, \mathrm{S}$ elements) with a dry extract comprised between 90 and 110 g.L $\mathrm{L}^{-1}$. Detailed compositions of studied leachates are given in Supplementary Fig. 1. In this work, leachates were incorporated into an acidic sol containing silica precursors and surfactants before the atomization step. Due to the high concentration variability of leachates, we chose to work at the following constant mass ratio:

$\mathrm{m}_{\text {surfactants }} /\left(\mathrm{m}_{\text {added SiO2 }}+\mathrm{m}_{\text {leachate dry extract }}\right)=1.12$

This mass ratio corresponds to the optimal ratio obtained for reference materials, i.e., without dry extract, 
in term of high specific surface area and porous volume. As the quantity of leachate dry extract incorporated in the final material is of prime importance in terms of valorization and economic viability, it was necessary to adapt the amount of silica precursor to that of dry extract of leachates. Thus, the mass percentage of leachate dry extract in the final calcined particles (2) studied in this article was $25 \%, 50 \%$ and $75 \%$.

$$
\mathrm{wt} \% \text { leacheate }=100 * \mathrm{~m}_{\text {leachate dry extract }} /\left(\mathrm{m}_{\text {added SiO2 }}+\mathrm{m}_{\text {dry extract }}\right)
$$

Particles with incorporated leachate were synthesized as follows. First, $8.8 \mathrm{~g}$ of Brij 58 surfactant were added in $164 \mathrm{~mL}$ of milli-Q water at $\mathrm{pH}=2$, acidification being done with $37 \mathrm{wt} \% \mathrm{HCl}$ and the solution were left under magnetic stirring at room temperature until surfactant dissolution. Next, $27.1 \mathrm{~g}$ TEOS $\left(\mathrm{Si}(\mathrm{OEt})_{4}\right)$ was added to the acidic surfactant solution and stirring was maintained for at least $2 \mathrm{~h}$ to complete hydrolysis-condensation reactions. In order to comply with the structuring agent mass ratio (Eq. (1)) the necessary quantity of surfactant based on the amount of leachate dry extract and the desired proportions of dry extract (needed to produce particles with $25 \%, 50 \%$ and $75 \%$ by weight of leachate dry extract after calcination) was added to the solution containing TEOS and Brij 58 . After 10 minutes of stirring, the resulting solution was atomized with a Büchi B290 apparatus. The solution was atomized with a two-fluid nozzle (liquid tip diameter $0.7 \mathrm{~mm}$ ) mixing solution at $0.36 \mathrm{~L} . \mathrm{h}^{-1}$ flow rate and compressed dry air at $670 \mathrm{~L}^{-\mathrm{h}^{-1}}$ flow rate. Hot air set at $180^{\circ} \mathrm{C}$ was used to dry solution droplets, (a flow rate of $34 \mathrm{~m}^{3} / \mathrm{h}$ was used). With this setting, the outlet temperature (air containing dry particles) was $90^{\circ} \mathrm{C}$.

Reference particles, e.g., without leachate dry extract, were also synthesized following the same protocol. Spraydried particles were then calcined at temperatures of 300 , 350,400 and $450{ }^{\circ} \mathrm{C}$ for $2 \mathrm{~h}$ in a furnace. For this step, we loosely capped the powder crucible with an alumina plate in order to limit the oxidation of carbonaceous species. This calcination protocol was initially chosen in order to obtain an optimum porosity while preserving a certain amount of residual carbonaceous species for promoting a more significant adsorption capacity of model pollutant compounds. In a few cases, calcined particles were washed three times with milli-Q water and thus filtered in order to remove water-soluble inorganic salts.

Porosimetry analyses were performed by nitrogen physisorption with an ASAP 2010 from Micromeritics; a standard 93-point program was used. Surface areas were determined with the BET model and pore size distributions were calculated with the BJH model using the desorption curve.

\subsubsection{Electron Microscopies SEM, TEM}

Pictures were obtained by using a TEM from Tecnai G2 Spirit Twin, operating at a standard voltage of $120 \mathrm{~kW}$ with an Orius 1000 Gatan $4 \mathrm{~K}$ x $4 \mathrm{~K}$ camera at the bottom of the column with equipment for tomography and cryotem. SEMFEG images were obtained using a Zeiss SUPRA 40 FESEM, operating at $2.5 \mathrm{kV}$

\subsubsection{XRD}

XRD measurements were carried out using a Bruker D8 Advance diffractometer equipped with a $\mathrm{Cu}$ anode $(\mathrm{K} \alpha=$ $8047.8 \mathrm{eV}$ ).

$\mathrm{X}$-Ray Fluorescence analyses were performed with a S8 Tiger $4 \mathrm{~kW}$ from Bruker.

\subsubsection{DCB adsorption tests}

Two tests of DCB adsorption have been performed using a model pollutant (1, 2 dichlorobenzene - DCB) for mimicking the chemical affinity of dioxin molecules in the literature [14]. The first one involved an atmosphere saturated in DCB and the second one was realized at lowpressure of DCB. Before adsorption tests, powders were treated at $130^{\circ} \mathrm{C}$ for $16 \mathrm{~h}$ in order to remove volatile species (water and other impurities). The tests carried out at DCB saturation were performed in hermetically sealed glass bottles at $130{ }^{\circ} \mathrm{C}$ for $10 \mathrm{~h}$. Such temperature and pressure mimic real adsorption conditions of adsorbates into the filter hose of incineration plants. Two vials were placed into bottles, one containing $0.5 \mathrm{~g}$ of adsorptive powder and the other containing $0.3 \mathrm{~g}$ DCB liquid. The amount of DCB adsorbed into the powders was calculated by weighing difference. Each experiment was carried out 10 times with different samples of the same batch of powders in order to minimize measurement uncertainty. The calculated mass of adsorbed DCB was confirmed by TGA analysis.

An IGA gravimetric vapor sorption analyzer supplied by Hiden Isochema Ltd. was used to perform the low-pressure adsorption tests. It consists of a high precision microbalance with a $0.1 \mu \mathrm{g}$ weight resolution, placed in a high vacuum chamber with computer-controlled temperature and pressure regulation capacities. Approximately $100 \mathrm{mg}$ of sample was placed in a quartz cradle attached to the microbalance and degassed at $130{ }^{\circ} \mathrm{C}$ for $10 \mathrm{~h}$ prior to the experiment. DCB vapors were generated in a vessel heated at the same regulation temperature as the microbalance, namely $55^{\circ} \mathrm{C}$. Therefore, the upper limit of attainable pressures is set by the saturated pressure of DCB at this temperature $(0.6646$ $\mathrm{kPa}$ ), leading to a maximum value for $\mathrm{P} / \mathrm{P}_{0}$ of $\sim 0.4$ at $60{ }^{\circ} \mathrm{C}$ and $\sim 0.1$ at $100{ }^{\circ} \mathrm{C}$. The temperature of the sample was regulated via a waterbath for adsorptions at $60^{\circ} \mathrm{C}$ and via a 
high-temperature furnace for adsorptions at $100^{\circ} \mathrm{C}$, allowing a control within $\pm 0.1{ }^{\circ} \mathrm{C}$. The DCB pressure was maintained to the target value during mass uptake which was monitored for at least $10 \mathrm{~min}$. A stretched exponential model was used to fit the uptake curves in real time and extrapolate the equilibrium mass when applicable. A timeout of 120 min was used for cases that did not match the used model.

\section{Results and discussion}

Powders containing trapped solid leachate display after atomization a yellow-green color whose intensity increases with the percentage of incorporated waste residue regardless of the leachate used, with the reference remaining white. Based on chemical analysis data of leachates, this color could be attributed to the presence of iron (II) and iron (III) compounds most probably complexed with chloride anions. After the calcination step, we observe that the pure silica reference remains dark brown whatever the calcination temperature (Fig. 1). Usually, mesoporous silica particles obtained with surfactants as templating agent present a white color after calcination and this dark brown color can be explained by our calcination protocol which implies a lower atmospheric $\mathrm{O}_{2}$ content. After a treatment at $300{ }^{\circ} \mathrm{C}$, no difference is observed between the reference and samples containing solid leachate. From $350^{\circ} \mathrm{C}$, sample colors are changing. Samples containing $25 \mathrm{wt} \%$ of leachate dry extract become increasingly light which could be due to the presence of iron oxide (vide infra) and alkali elements in the leachate. Indeed, iron oxides have shown interesting catalytic activity in the oxidation of soot, whether magnetite, hematite, or potassium ferrate, in the form of nanoparticles, supported or not [15-19].

Figure 2 shows the powder morphologies after a calcination step at $300^{\circ} \mathrm{C}$ (no difference is observed at higher temperature). According to SEM experiments, the reference powder essentially consists of well-dispersed micrometricsize spherical particles as expected with spray-dried materials. With the incorporation of increasing amount of leachate dry extract, one could observe a loss of spherical morphology and an increase of particles aggregation from $50 \mathrm{wt} \%$. This observation is very probably due to a loss of inorganic network rigidity at the end of the drying step, leading to a partial coalescence of particles. The use of high drying temperature is likely to limit this evolution of the morphology. We highlight that the very high salt concentration of heavily loaded materials is likely (i) to maintain a fairly high content of water within particles in atmospheric conditions, and (ii) to soften the inorganic matrix during the calcination step. Both can affect the macroscopic morphology of the materials and may also disturb their mesoscopic structure. More insight on this point is given by gas physisorption analyses.

As previously mentioned, we used nitrogen physisorption analyses to evaluate the effects of the temperature of the calcination step and relative amount of leachate dry
Fig. 1 Pictures of powders obtained after calcination. Ref corresponds to the silica-based reference powder only. The percentages correspond to the weight percentages of leachate dry extract in calcined powders
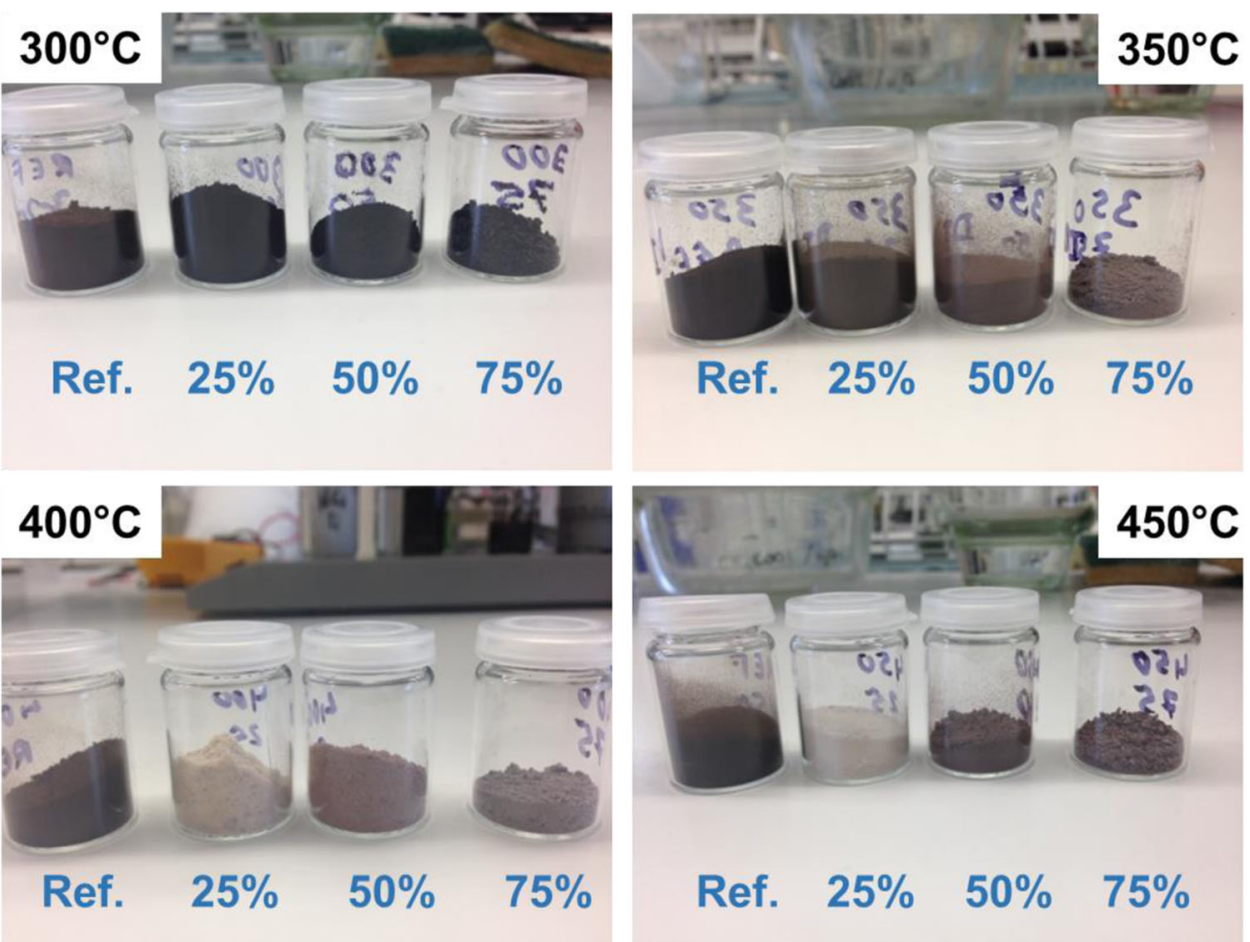

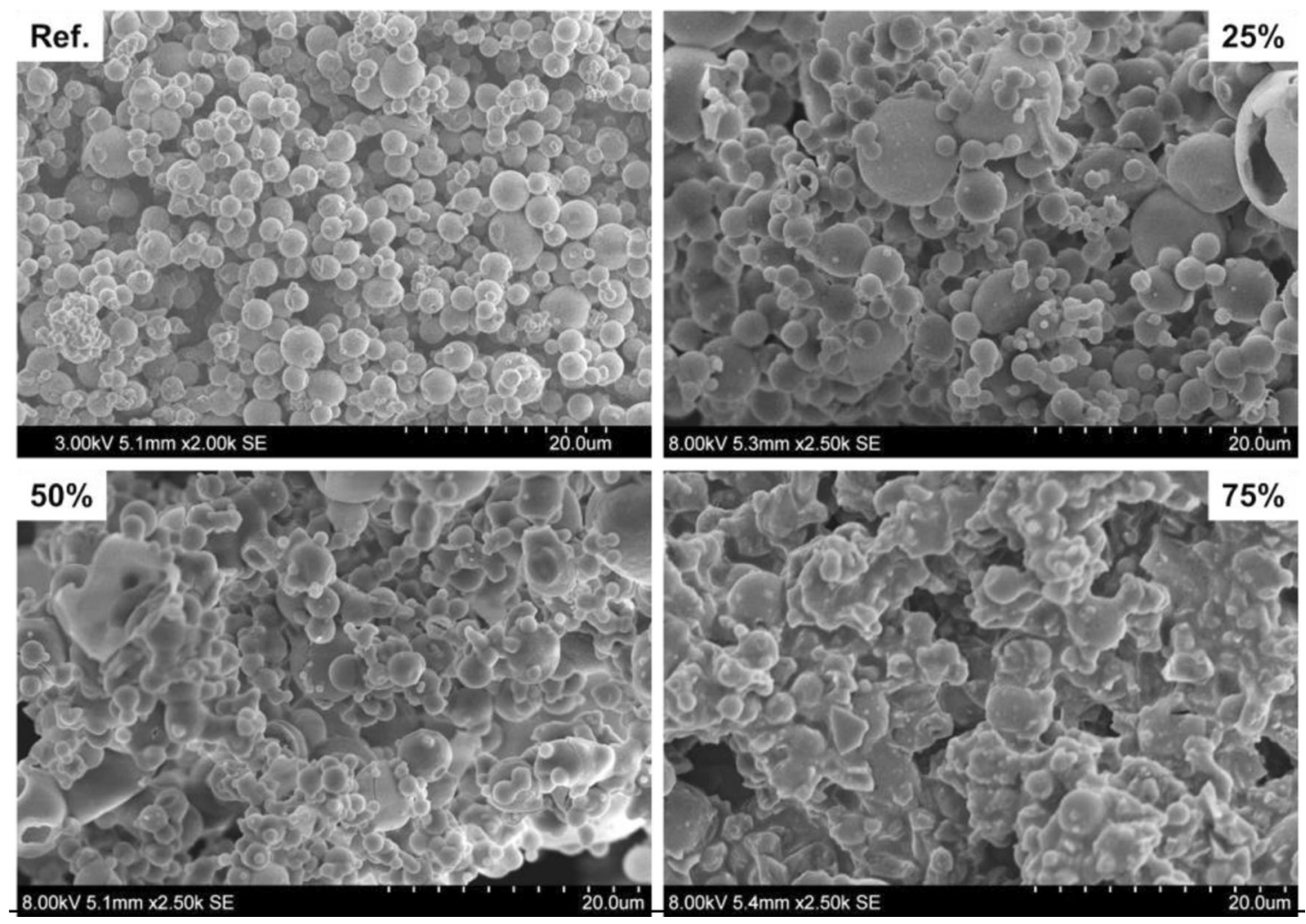

Fig. 2 2.50 K magnification SEM images of reference powder and powders containing leachate dry extract at 25, 50 and $75 \mathrm{wt} \%$. All samples were calcined at $300^{\circ} \mathrm{C}$

extract on textural properties (e.g., specific surface area, porous volume and pore size distribution) of particles. Figure 3 presents nitrogen adsorption-desorption isotherms as a function of powders calcination temperature for a given material. Most of the nitrogen physisorption isotherms obtained are type IV except in the case of the last sample (75 wt \% of dry extract) which is a mix of types II and IV isotherms according to IUPAC considerations [20]. The incorporation of increasing quantities of dry extract (50 and $75 \mathrm{wt} \%$ ) yields a progressive loss of the meso-organization (widening of the range of relative pressure where capillary condensation occurs, indicating a widening of the pore size distribution) as well as a decrease in the specific surface area and porous volume.

Concerning the purely silicic reference (Fig. 3), isotherms comply with what is classically obtained with this type of system, i.e., a high specific surface area of the order of $500-600 \mathrm{~m}^{2} \cdot \mathrm{g}^{-1}$, a narrow pore size distribution of the order of $3 \mathrm{~nm}$ and a porous volume of $\sim 0.5-0.6 \mathrm{~cm}^{3} \cdot \mathrm{g}^{-1}$. It should be noted that the textural characteristics change significantly between $350{ }^{\circ} \mathrm{C}$ and $400{ }^{\circ} \mathrm{C}$ which corresponds to a more complete degradation of Brij 58 (few differences are observed between $300^{\circ} \mathrm{C}$ and $350{ }^{\circ} \mathrm{C}$ and between $400{ }^{\circ} \mathrm{C}$ and $450{ }^{\circ} \mathrm{C}$ ).

Concerning material containing $25 \mathrm{wt} \%$ of leachate solids (Fig. 3), the same observations as for the purely silicic reference could be made with the exception of two details. First, the specific surface areas are larger than in the case of the purely silicic reference for all calcination temperatures except $450{ }^{\circ} \mathrm{C}$. One could therefore wonder whether the presence of certain elements in the dry extract could promote a better meso-organization or could catalyze the degradation of the Brij 58 soot thus generating more porosity as previously mentioned (for example iron oxide and alkali elements). The second difference appears in the powder calcined at $450{ }^{\circ} \mathrm{C}$ which is characterized by a decrease in specific surface area compared to other calcination temperatures while remaining comparable to that of the reference. We also observed that specific surface areas decreased as the calcination time increased (results not shown in this paper). These observations could be attributed to the presence of fluxing agents $\left(\mathrm{Na}^{+}, \mathrm{K}^{+}\right)$within the leachate which promote a depolymerization of the silica network and a collapse of the mesoporosity. Finally, we can conclude that the addition of $25 \%$ by mass of dry extract does not seem to drastically modify the pore size distribution.

The most notable differences with respect to the isotherms of the silicic reference are observed for powders obtained with $50 \mathrm{wt} \%$ and $75 \mathrm{wt} \%$ of dry extract which present an optimum specific surface area for calcination temperature of $350^{\circ} \mathrm{C}$ (Fig. 3). We could notice also that 

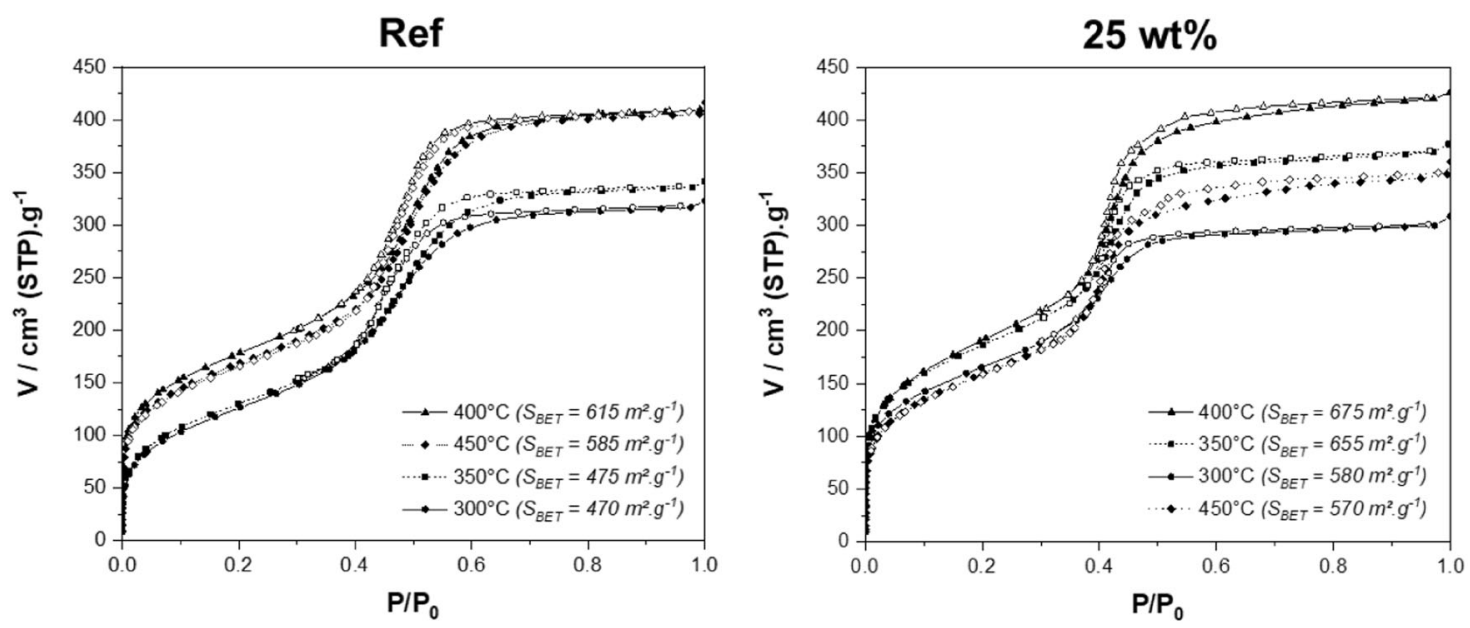

\section{$50 \mathbf{w t} \%$}
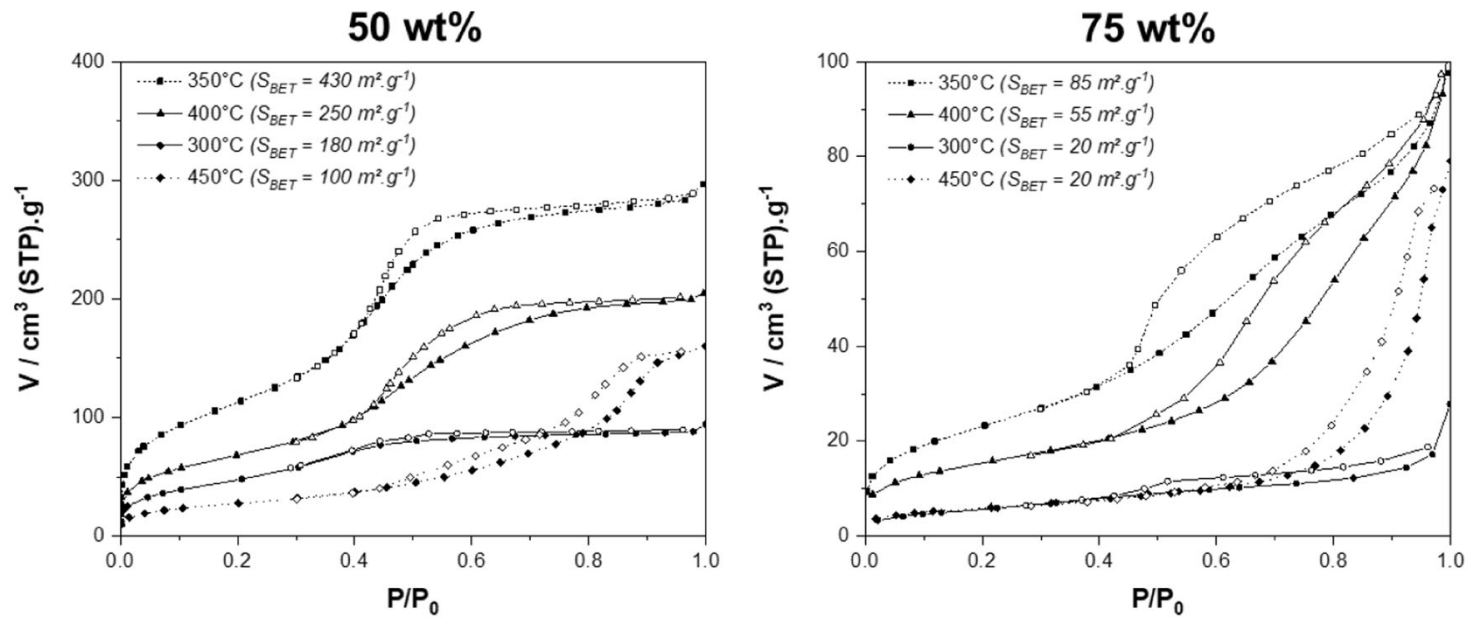

Fig. $3 \mathrm{~N}_{2}$ adsorption-desorption isotherms of the reference powder, and powders containing $25 \mathrm{wt} \%, 50 \mathrm{wt} \%$ and $75 \mathrm{wt} \%$ of leachate dry extract, following calcination between $300^{\circ} \mathrm{C}$ and $450{ }^{\circ} \mathrm{C}$

the specific surface area at $300{ }^{\circ} \mathrm{C}$ for these two samples are very low compared to those of the reference and the sample at $25 \%$ especially if one considers that the presence of leachate cations has a catalytic effect on the degradation of organic compounds [15-19]. It seems thus that the presence of incorporated dry extract in high amount has either (i) a destabilizing effect with respect to the process of mesoorganization (phase segregation, presence of fluxes, pore blocking), and/or (ii) that the massive amount of iron, aluminum and calcium cations present in the leachate stabilizes organic compounds up to $300{ }^{\circ} \mathrm{C}$. This observation should be put in perspective with TGA analysis (Supplementary Fig. 2) since we notice a mass loss of surfactant at higher temperature in the presence of high level of dry extract, suggesting a stabilizing effect of dry extract species on surfactant decomposition. At $350{ }^{\circ} \mathrm{C}$, the powder containing $50 \mathrm{wt} \%$ of dry extract exhibits textural characteristics close to those of the reference (slightly smaller surface area, lower pore volume and larger pore size distribution) which agrees with the loss of organic species (Supplementary Fig. 2). From $400{ }^{\circ} \mathrm{C}$, there is a noticeable loss of mesoorganization (larger pore size distribution, smaller specific surface area and pore volume). We observe the same behavior for the sample containing $75 \mathrm{wt} \%$ of dry extract but with a much stronger effect. Such an effect is often observed during the synthesis of mesostructured materials based on transition metals, where the crystallization of the inorganic phase tends to be detrimental for the mesoporosity [21-23].

Another purely physicochemical effect also helps to explain part of the decrease in specific surface areas and pore volumes when the dry extract content increases. Indeed, the incorporation of elements with a higher density than silica reduces globally specific surface area and pore volume values (for they are both normalized per gram of matter). We can thus conclude that the incorporation of leachate affects the texture of the materials in two ways: it could (i) disturb the self-assembling process taking place 

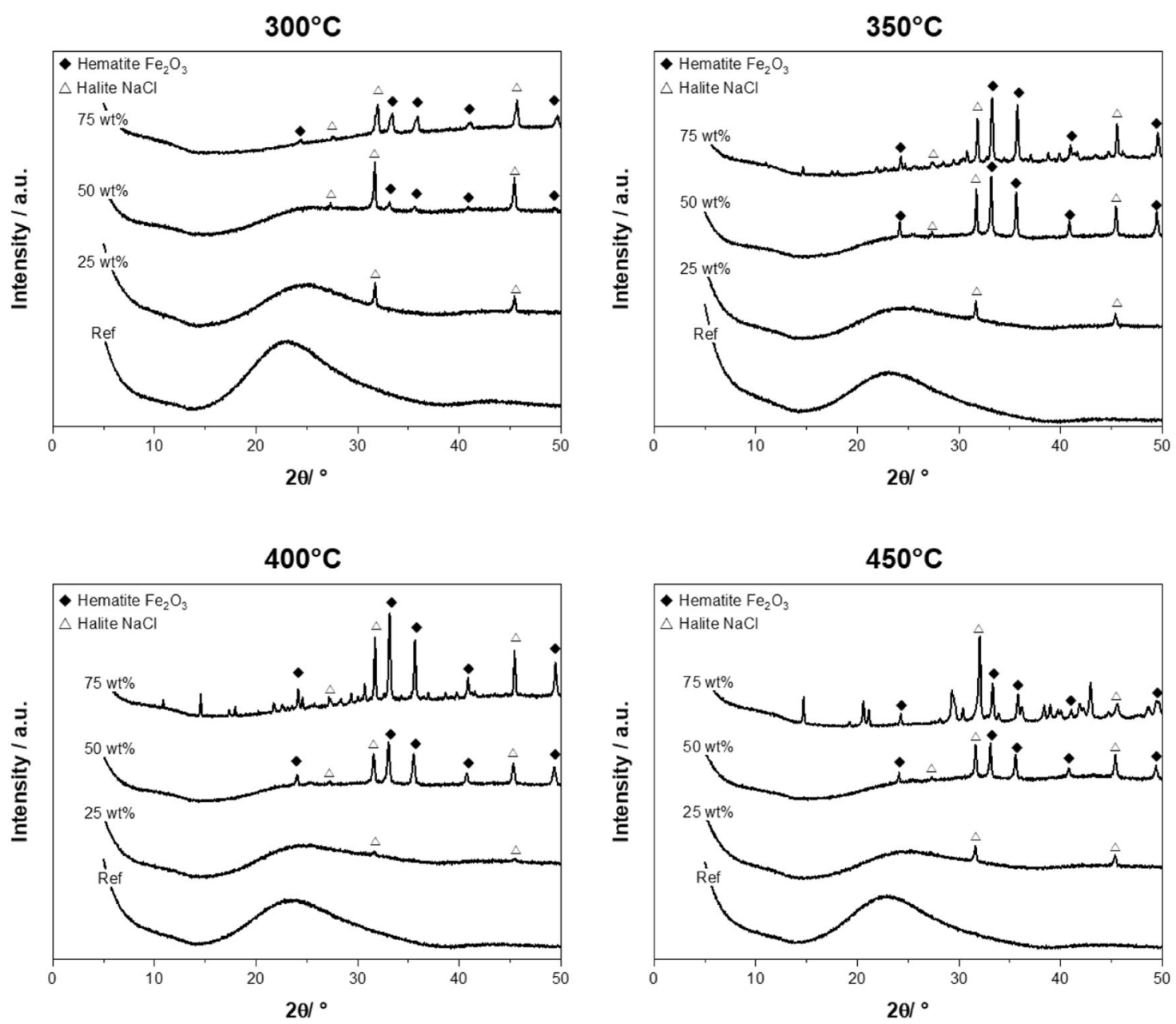

Fig. 4 Diffractograms of powders calcined at $300{ }^{\circ} \mathrm{C}, 350{ }^{\circ} \mathrm{C}, 400{ }^{\circ} \mathrm{C}$ and $450{ }^{\circ} \mathrm{C}$

during spray drying if $50 \mathrm{wt} \%$ of dry extract or higher is incorporated, and (ii) cause phase segregations inside silicabased particles (presence of inorganic salts and transition metal oxides, for example). Thus, we performed XRD and TEM analyses in order to know if the phase segregation phenomenon could be observed after the atomization and calcination steps.

The analysis of the different powders by X-ray diffraction reveals a number of interesting facts. First of all, as expected the purely silicic reference is amorphous and characterized by a large scattering hump centered at $22^{\circ}-23^{\circ}$ in $2 \theta$ (Fig. 4). It gradually disappears when the dry matter content increases in favor of crystalline structures, whatever the calcination temperatures, these structures being all more present as leachate dry extract content increases. At $300^{\circ} \mathrm{C}$, only two crystalline compounds are present: halite $\mathrm{NaCl}$ for all powders containing dry extract and hematite $\mathrm{Fe}_{2} \mathrm{O}_{3}$ for powders containing $50 \%$ and $75 \%$ dry extract. While the presence of $\mathrm{NaCl}$ is rather neutral with respect to the self-assembly process and sol-gel reactions involved in the Evaporation-Induced SelfAssembly (EISA) pathway [22, 24] (and can even serve as a pore-forming agent [25]), the presence of iron oxides can modify the textural characteristics of powders especially during their crystallization, which causes a reorganization of matter on a larger scale than the characteristic periodicity of the mesoporous network [21-23]. From $350{ }^{\circ} \mathrm{C}$ and only for the powder containing the highest extract content (75\%), the diffractogram becomes more complex with the appearance of numerous peaks in addition to those previously assigned to halite and hematite.

Finally, from Scherrer's formula, we were able to estimate the size of the crystallites of $\mathrm{NaCl}$ and $\alpha-\mathrm{Fe}_{2} \mathrm{O}_{3}$ present in the powders (Supplementary Table 1). First of all, it is observed that the crystallites are of nanometric size of the order of $40-50 \mathrm{~nm}$ in diameter for $\mathrm{NaCl}$ and $\alpha-\mathrm{Fe}_{2} \mathrm{O}_{3}$. These dimensions do not seem to evolve much with the calcination temperature, which demonstrates a good dispersion of dry extract species within particles. It also appears that this size is larger than Brij 58 micelles (diameter of the order of 

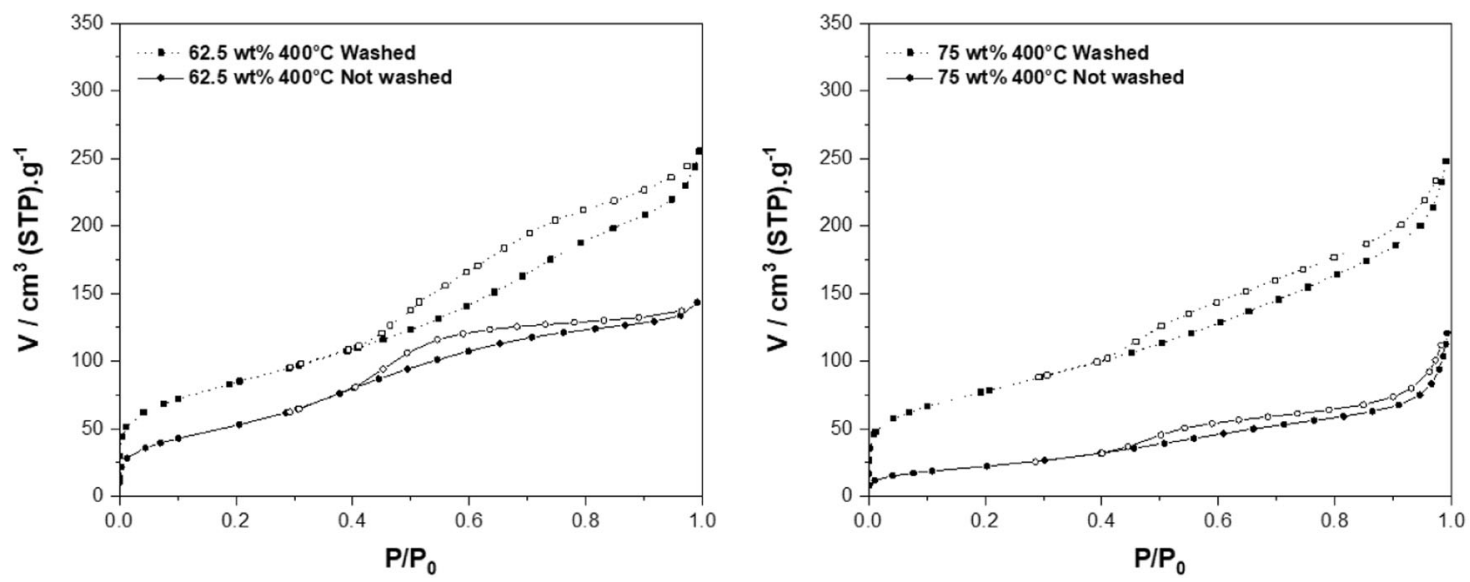

Fig. $5 \mathrm{~N}_{2}$ adsorption-desorption isotherms before and after milli-Q water washing for particles calcined at different temperatures with a 62.5 and $75 \mathrm{wt} \%$ content of leachate dry extract

2-4 nm) which could explain partially the loss of specific surface area and porous volume observed when the dry extract content increases [26]. TEM analyses confirm a well-organized mesophase at low dry extract content and a progressive loss of ordering when leachate content increases (Supplementary Fig. 3). We observe also phase segregation on TEM pictures with an increase of this phenomenon when dry extract content increases. One can conclude at this step that the kinetics of sol-gel reactions and atomization process seem to favor phase nanosegregation of different species (salts and metallic oxides) resulting in materials where nanoparticles formed are accessible to external media via mesoporous channels.

As from economic and bottom ash recycling point of view, the optimum material is likely to be the best compromise in between high surface area and high amount of leachate incorporated. Hence, it is interesting to study the influence of water washing (for removing highly soluble salts) on textural characteristics especially for materials with high leachate content. Indeed, industrial references used for treating flue gas in modern incineration plants are microporous carbonbased materials such as activated carbon NORIT ${ }^{\circ}$ GL 50 or Lignite $\mathrm{HOK}^{\bullet}$ - Super which display a specific surface area of 650 and $300 \mathrm{~m}^{2} \cdot \mathrm{g}^{-1}$, respectively. Here, the washing step allows surface area enhancement of $150-300 \mathrm{~m}^{2} \cdot \mathrm{g}^{-1}$ without apparent collapsing and to reach specific surface area of $300 \mathrm{~m}^{2} \cdot \mathrm{g}^{-1}$ (Fig. 5) for a sample prepared with $62.5 \mathrm{wt} \%$ of dry extract. This surface enhancement depends also on the amount of inorganic salts in particles and is most of the time greater for high leachate loadings. It depends also on the leachate concentration in inorganic salts but in this case, it is hardly controllable since it is directly correlated to the concentration/composition of industrial and household wastes. As evidenced with XRD experiments, only peaks attributed to $\alpha-\mathrm{Fe}_{2} \mathrm{O}_{3}$ nanoparticles remain in XRD diffractograms after washing (Supplementary Fig. 4) and X-ray fluorescence spectrometry performed on powders before and after the washing step demonstrate a decrease of $\mathrm{Na}, \mathrm{Mg}, \mathrm{Cl}, \mathrm{Ca}$ content (mainly $\mathrm{Ca}$ and $\mathrm{Cl}$, Supplementary Fig. 5). This result confirms the accessibility of leachate-based nanoparticles to surrounding media (here water and nitrogen gas).

From this point, we evaluated adsorption capacity of our powders for polychlorobenzene (PCB) and dioxin pollutant with a model pollutant molecule (1,2-dichlorobenzene DCB). We studied powders made with 50, 62.5 and $75 \mathrm{wt} \%$ previously calcined at 350 and $400{ }^{\circ} \mathrm{C}$ and washed with milli-Q water. The choice to synthesize and to test an intermediate composition (e.g., $62.5 \mathrm{wt} \%$ ) is related to the compromise previously mentioned between high surface area and high leachate dry extract content. A first series of adsorption experiments (10 adsorption tests for a given material calcined at 350 or $400{ }^{\circ} \mathrm{C}$ after an activation step at $130{ }^{\circ} \mathrm{C}$ over $10 \mathrm{~h}$ ) was performed at $130{ }^{\circ} \mathrm{C}$ to conform with temperatures encountered in filtration units with an atmosphere saturated with gaseous DCB. The results of adsorption tests are gathered in Fig. 6.

We observed first that pure carbonaceous mesoporous reference powders $(0 \mathrm{wt} \%)$ present the best DCB adsorption capacity, slightly better than the benchmark material e.g., activated carbon NORIT $^{\circ}$ GL 50 and are much more efficient than the Lignite $\mathrm{HOK}^{\circ}$ - Super. Powders containing 50 and $62.5 \mathrm{wt} \%$ of leachate display an intermediate performance between the two commercial adsorptive products and thus could be considered as good candidate for further investigations at larger scale. Concerning samples at $75 \mathrm{wt} \%$, adsorption capacity is slightly lower than the Lignite HOK ${ }^{\circ}$ - Super. And finally, materials synthesized with leachate and Brij 58 only present the lowest adsorption ability of all the samples tested. This low adsorption could be explained in regard to their very low specific surface area $\left(\mathrm{S}_{\mathrm{BET}} 350^{\circ} \mathrm{C}=50 \mathrm{~m}^{2} \cdot \mathrm{g}^{-1}\right.$ and $S_{\mathrm{BET}} 400^{\circ} \mathrm{C}=30 \mathrm{~m}^{2} \cdot \mathrm{g}^{-1}$ ) despite $\pi$-interactions between the DCB aromatic ring and iron oxides [27]. If adsorptive 


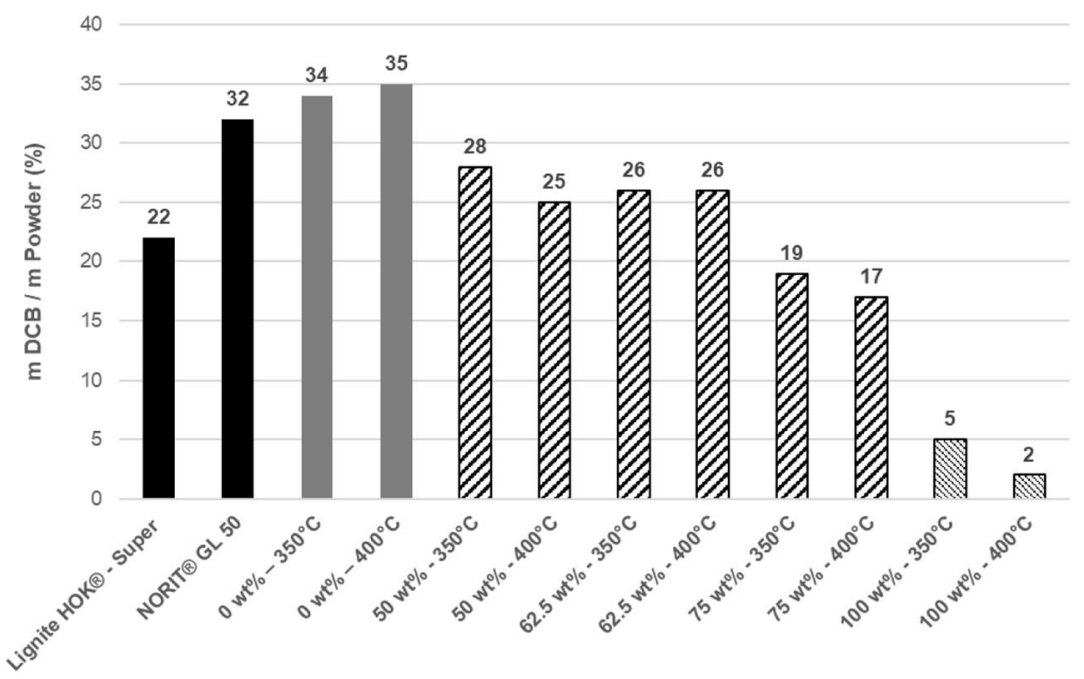

Fig. 6 DCB adsorption tests in saturated conditions carried out on two commercial adsorptive powders (Lignite HOK $^{\oplus}$ - Super and NORIT GL 50), two porous references (e.g., without leachate dry extract namely $0 \mathrm{wt} \%$ ), samples containing 50, 62.5 and $75 \mathrm{wt} \%$ of leachate dry extract and finally powders synthesized with leachate dry extract and Brij 58 only (e.g., without TEOS precursor). Each test was performed ten times with different samples of the same powder. The resulting standard deviation for each series was comprised between 1 and $2 \%$. Mass adsorption experiments were confirmed by TGA analyses
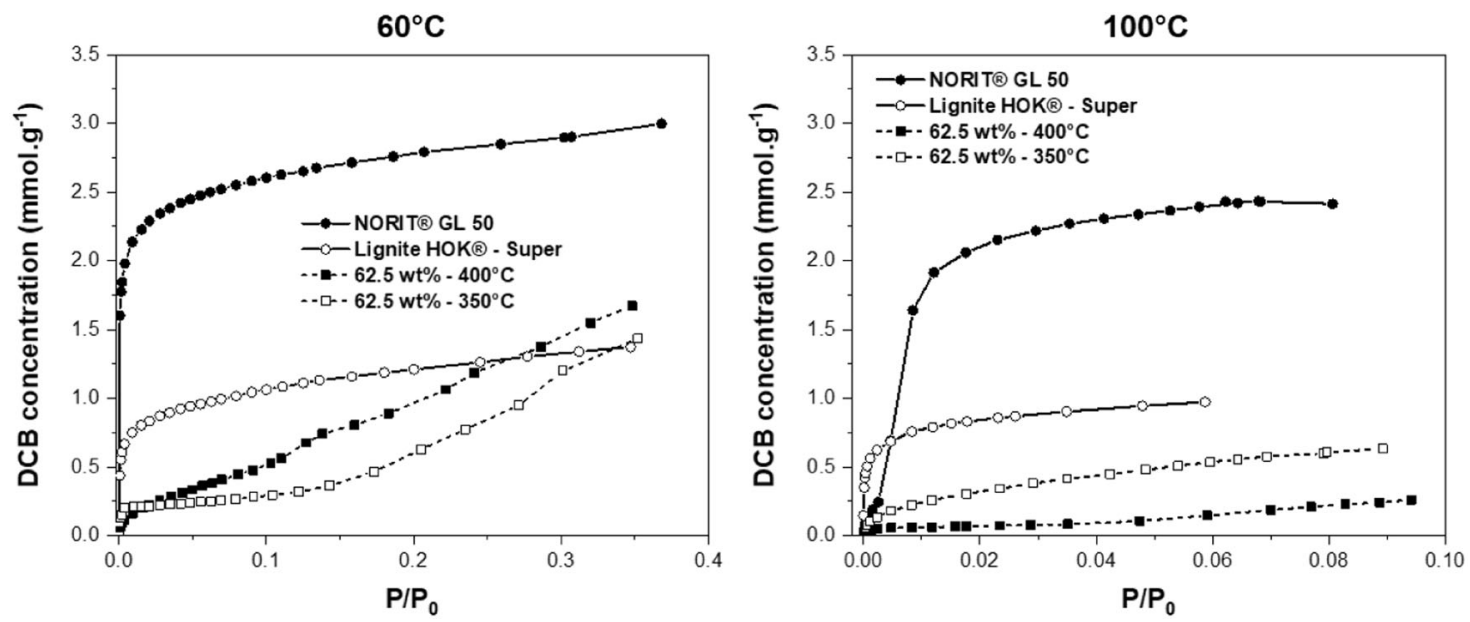

Fig. 7 DCB adsorption isotherm obtained at $60{ }^{\circ} \mathrm{C}$ and $100^{\circ} \mathrm{C}$ on the two commercial adsorptive powders (Lignite HOK ${ }^{\oplus}$ - Super and NORIT ${ }^{\oplus}$ GL 50) and on powders containing $62.5 \mathrm{wt} \%$ of leachate dry extract calcined at $350{ }^{\circ} \mathrm{C}$ and $400{ }^{\circ} \mathrm{C}$

performances should be at least equal to those of Lignite HOK $^{\oplus}$ - Super, materials having a composition in between 62.5 and $75 \mathrm{wt} \%$ should be researched. However, from a business point-of-view, many other variables are involved when considering proper cost/performance/ecological impact evaluation. Due this complexity, even the materials with larger quantity of by-products incorporated but less outstanding performance could have their own market.

After these first DCB adsorption tests in saturated atmosphere, we selected the sample at $62.5 \mathrm{wt} \%$ of leachate dry extract to determine adsorption isotherms at $60^{\circ} \mathrm{C}$ and $100{ }^{\circ} \mathrm{C}$ (Fig. 7).
Here again, the best performances at low relative pressure are achieved by the NORIT ${ }^{\circ}$ GL 50 followed by the Lignite $\mathrm{HOK}^{\circ}$ - Super. Low-pressure adsorption properties (e.g., $\left.\mathrm{P} / \mathrm{P}_{0}<0.1\right)$ are not drastically impacted by temperatures of adsorption between 60 and $100{ }^{\circ} \mathrm{C}$. At higher $\mathrm{P} / \mathrm{P}_{0}$ (e.g., $\mathrm{P} / \mathrm{P}_{0}>0.25$ ), we observed that the $62.5 \mathrm{wt} \%$ materials display better DCB adsorption properties than Lignite HOK $^{\circ}$ - Super. This behavior has been previously described in a study comparing dioxin adsorption properties of commercial microporous activated carbons (NORIT ${ }^{\oplus}$ GL 50 and EVN.2) and mesoporous MTS (micelle-templated silicas) materials [28]. Thus, microporosity seems to have a positive 
influence on low-pressure adsorption of organic pollutant like dioxin whereas mesoporosity promotes high adsorption at higher relative pressure. Then, in order to compete wholly with activated carbons, it could be interesting to promote also microporosity in materials. More globally, dioxins and heavy PCB molecules have low or very low volatility at the operating temperature of filtration units (for example, Seveso dioxin has a boiling point $>400^{\circ} \mathrm{C}$ ). These pollutants are produced intermittently at high temperature in incineration furnaces $\left(850^{\circ} \mathrm{C}\right.$ or higher). Even though their concentration in flue gas is unknown (due to the lack of dedicated on-line sensors), their volatility at $130^{\circ} \mathrm{C}$ is likely to be extremely low. In other words, in filtration units, their relative pressure should be fairly high, thus adsorptive materials with high mesoporous surface are, a priori, good candidates for their adsorption.

\section{Conclusion}

Human activity produces an extremely large amount of waste with only a small fraction being recycled. After landfilling, incineration remains the second way for treating industrial and household wastes with high mass and volume reductions. However, this combustion process induces emissions of pollutants and accumulation of final solid byproducts, both being controlled and collected in modern incineration plants. The reuse of bottom ash in construction applications has become a standard practice especially for road construction. But its environmental impact on flora and fauna coupled with regulatory restrictions requires alternatives other than landfilling which is today the only economically viable alternative.

This article addresses a global disruptive process aiming at transforming incineration by-product into recoverable raw materials. Being originally wastes, incineration materials obtained via this systemic process can be reintroduced into conventional industrial sectors, thus promoting a circular economy and reducing natural resources wastage. Treatment of industrial and household wastes allows operators to extract and purify raw materials of interest which are technically competitive with mineral ores. This means that waste could be (and should be) considered as a source of raw materials close to final consumers without involving large transportation distances.

More specifically, we described an innovative process combining templated sol-gel growth of an inorganic or hybrid silica-based network with a solubilized fraction of bottom ash. The resulting materials engineered via aerosol processing demonstrate adsorption properties of model organic pollutants at the level of the activated carbons already used in the current modern incineration plants. Despite variation in terms of leachate species concentration, our synthetic pathway is sufficiently reliable for producing reproducible particles whatever the origin of the initial waste. At the laboratory scale, this global process allows recycling of nearly $80 \mathrm{wt} \%$ of the initial amount of bottom ash while being economically interesting. Therefore, these aerosol-processed functional mineral adsorbents could have a future for replacing conventional carbon adsorbents currently used in incineration plants.

\section{Compliance with ethical standards}

Conflict of interest The authors declare no competing interests.

Publisher's note Springer Nature remains neutral with regard to jurisdictional claims in published maps and institutional affiliations.

Open Access This article is licensed under a Creative Commons Attribution 4.0 International License, which permits use, sharing, adaptation, distribution and reproduction in any medium or format, as long as you give appropriate credit to the original author(s) and the source, provide a link to the Creative Commons license, and indicate if changes were made. The images or other third party material in this article are included in the article's Creative Commons license, unless indicated otherwise in a credit line to the material. If material is not included in the article's Creative Commons license and your intended use is not permitted by statutory regulation or exceeds the permitted use, you will need to obtain permission directly from the copyright holder. To view a copy of this license, visit http://creativecommons. org/licenses/by/4.0/.

\section{References}

1. Kaza S, Yao LC, Bhada-Tata P, Van Woerden F (2018) What a waste 2.0: a global snapshot of solid waste management to 2050 . Urban Development: Washington, DC: World Bank. https://doi. org/10.1596/978-1-4648-1329-0

2. Giusti L (2009) A review of waste management practices and their impact on human health. Waste Manag 29(8):2227-2239. https:// doi.org/10.1016/j.wasman.2009.03.028

3. Tillman DA, Rossi AJ, Vick KM (1989) Incineration of municipal and hazardous solid wastes. Elsevier Science. https://doi.org/10. 1016/B978-0-12-691245-6.X5001-9

4. Silva RV, de Brito J, Lynn CJ, Dhir RK (2019) Environmental impacts of the use of bottom ashes from municipal solid waste incineration: a review. Resour Conserv Recycling 140:23-35. https://doi.org/10.1016/j.resconrec.2018.09.011

5. Brunner PH, Rechberger H (2015) Waste to energy - key element for sustainable waste management. Waste Manag 37:3-12. https:// doi.org/10.1016/j.wasman.2014.02.003

6. Morselli L, Passarini F, Bartoli M (2002) The environmental fate of heavy metals arising from a MSW incineration plant. Waste Manag 22(8):875-881. https://doi.org/10.1016/S0956-053X(02)00073-9

7. Liu A, Ren F, Lin WY, Wang J-Y (2015) A review of municipal solid waste environmental standards with a focus on incinerator residues. Int J Sustain Built Environ 4(2):165-188. https://doi.org/ 10.1016/j.ijsbe.2015.11.002

8. Directive 2010/75/EU of the European Parliament and of the Council of 24 November 2010 on industrial emissions (integrated pollution prevention and control) OJ L 334, 2010, p. 17-119. http://data.europa.eu/eli/dir/2010/75/oj

9. Shih H-c MaH-w (2011) Assessing the health risk of reuse of bottom ash in road paving. Chemosphere 82(11):1556-1562. https://doi.org/10.1016/j.chemosphere.2010.11.061 
10. Dhir RK, De Brito J, Lynn CJ, Silva RV (2018) Sustainable construction materials: municipal incinerated bottom ash. Woodhead Publishing. https://doi.org/10.1016/C2015-0-00489-0

11. Lynn CJ, Ghataora GS, Dhir Obe RK (2017) Municipal incinerated bottom ash (MIBA) characteristics and potential for use in road pavements. Int J Pavement Res Technol 10(2):185-201. https://doi.org/10.1016/j.ijprt.2016.12.003

12. Sanchez C, Boissiere C, Nicole L, Baradari H, Chaucherie X, Gilardin B (2018) Method for producing a material with a large specific surface. FR3063658; WO2018162861,

13. Sanchez C, Boissiere C, Nicole L, Baradari H, Chaucherie X, Gilardin B (2019) Process for manufacturing a porous material from incineration clinkers. FR3071494; WO2019058086,

14. Bullot L, Abda MB, Simon-Masseron A, Jean Daou T, Chaplais G, Nouali H, Schäf O, Zerega Y, Fiani E, Patarin J (2017) Dioxin and 1,2-dichlorobenzene adsorption in aluminosilicate zeolite Beta. Adsorption 23(1):101-112. https://doi.org/10.1007/s10450016-9828-3

15. Wagloehner S, Kureti S (2012) Study on the mechanism of the oxidation of soot on $\mathrm{Fe} 2 \mathrm{O} 3$ catalyst. Appl Catal B Environ 125:158-165. https://doi.org/10.1016/j.apcatb.2012.05.032

16. Wagloehner S, Kureti S (2013) Modelling of the kinetics of the catalytic soot oxidation on $\mathrm{Fe} 2 \mathrm{O}$. Appl Catal B Environ 129:501-508. https://doi.org/10.1016/j.apcatb.2012.09.055

17. Wagloehner S, Baer JN, Kureti S (2014) Structure-activity relation of iron oxide catalysts in soot oxidation. Appl Catal B Environ 147:1000-1008. https://doi.org/10.1016/j.apcatb.2013.09.049

18. Legutko P, Kaspera W, Stelmachowski P, Sojka Z, Kotarba A (2014) Boosting the catalytic activity of magnetite in soot oxidation by surface alkali promotion. Catal Commun 56:139-142. https://doi.org/10.1016/j.catcom.2014.07.020

19. Stelmachowski P, Kopacz A, Legutko P, Indyka P, Wojtasik M, Ziemianski L, Zak G, Sojka Z, Kotarba A (2015) The role of crystallite size of iron oxide catalyst for soot combustion. Catal Today 257:111-116. https://doi.org/10.1016/j.cattod. 2015.02.018
20. Rouquerol F, Rouquerol J, Sing K (1999) Adsorption by powders and porous solids. Academic Press. https://doi.org/10.1016/B9780-12-598920-6.X5000-3

21. Boissiere C, Grosso D, Chaumonnot A, Nicole L, Sanchez C (2011) Aerosol route to functional nanostructured inorganic and hybrid porous materials. Adv Mater 23(5):599-623. https://doi. org/10.1002/adma.201001410

22. Sanchez C, Boissiere C, Grosso D, Laberty C, Nicole L (2008) Design, synthesis, and properties of inorganic and hybrid thin films having periodically organized nanoporosity. Chem Mater 20 (3):682-737. https://doi.org/10.1021/cm702100t

23. Debecker DP, Le Bras S, Boissiere C, Chaumonnot A, Sanchez C (2018) Aerosol processing: a wind of innovation in the field of advanced heterogeneous catalysts. Chem Soc Rev 47 (11):4112-4155. https://doi.org/10.1039/c7cs00697g

24. Brinker CJ, Lu Y, Sellinger A, Fan H (1999) Evaporation-induced self-assembly: nanostructures made easy. Adv Mater 11 (7):579-585. https://doi.org/10.1002/(SICI)1521-4095(199905) 11:7<579::AID-ADMA579>3.0.CO;2-R

25. Jiang XM, Brinker CJ (2006) Aerosol-assisted self-assembly of single-crystal core/nanoporous shell particles as model controlled release capsules. J Am Chem Soc 128(14):4512-4513. https://doi. org/10.1021/ja058260+

26. Chamieh J, Davanier F, Jannin V, Demarne F, Cottet H (2015) Size characterization of commercial micelles and microemulsions by Taylor dispersion analysis. Int J Pharmaceutics 492(1):46-54. https://doi.org/10.1016/j.ijpharm.2015.06.037

27. Joseph Y, Wühn M, Niklewski A, Ranke W, Weiss W, Wöll C, Schlögl R (2000) Interaction of ethylbenzene and styrene with iron oxide model catalyst films at low coverages: a NEXAFS study. Phys Chem Chem Phys 2(22):5314-5319. https://doi.org/ 10.1039/B006332K

28. Ottaviani MF, Mazzeo R, Turro NJ, Lei X (2011) EPR study of the adsorption of dioxin vapours onto microporous carbons and mesoporous silica. Microporous Mesoporous Mater 139 (1):179-188. https://doi.org/10.1016/j.micromeso.2010.10.040 